\title{
Revisiting the Physical Mechanisms of East Asian Summer Monsoon Precipitation Changes During the Mid-Holocene: A Data-model Comparison
}

\section{Yong Sun ( $\sim$ sunyong@mail.iap.ac.cn )}

Institute of Atmospheric Physics Chinese Academy of Sciences https://orcid.org/0000-0002-10876060

\section{Haibin Wu}

IGG CAS: Institute of Geology and Geophysics Chinese Academy of Sciences

\section{Gilles Ramstein}

LSCE: Laboratoire des sciences du climat et de l'environnement

\section{Bo Liu}

CUG: China University of Geosciences

\section{Yan Zhao}

ITPCAS: Institute of Tibetan Plateau Research Chinese Academy of Sciences

\section{Laurent Li}

LMD: Laboratoire de Meteorologie Dynamique

\section{Xiayu Yuan}

IAP CAS: Institute of Atmospheric Physics Chinese Academy of Sciences

\section{Wenchao Zhang}

IGG CAS: Institute of Geology and Geophysics Chinese Academy of Sciences

\section{Lijuan Li}

IAP CAS: Institute of Atmospheric Physics Chinese Academy of Sciences

\section{Liwei Zou}

IAP CAS: Institute of Atmospheric Physics Chinese Academy of Sciences

\section{Tianjun Zhou}

IAP CAS: Institute of Atmospheric Physics Chinese Academy of Sciences

\section{Research Article}

Keywords: Mid-Holocene, Monsoon precipitation, Water vapor budget, Thermodynamic effect, Dynamic effect, Cloud cooling effect

Posted Date: April 20th, 2021 
License: (c) (i) This work is licensed under a Creative Commons Attribution 4.0 International License. Read Full License 
1 Revisiting the physical mechanisms of East Asian Summer Monsoon

2 precipitation changes during the mid-Holocene: A data-model

3 comparison

4 Yong Sun ${ }^{1,2}$, Haibin Wu ${ }^{3,4,5}$, Gilles Ramstein ${ }^{2}$, Bo Liu', Yan Zhao ${ }^{7}$, Laurent Li $^{8}$, Xiayu

$5 \quad$ Yuan$^{9}$, Wenchao Zhang ${ }^{3}$, Lijuan Li ${ }^{1}$, Liwei Zou' ${ }^{1}$, Tianjun Zhou ${ }^{1,10}$

$7 \quad{ }^{1}$ State Key Laboratory of Numerical Modeling for Atmospheric Sciences and Geophysical

8 Fluid Dynamics, Institute of Atmospheric Physics, Chinese Academy of Sciences, Beijing

9 100029, China

$10{ }^{2}$ Laboratoire des Sciences du Climat et de l'Environnement, LSCE/IPSL, CEA - CNRS -

11 UVSQ, Université Paris - Saclay, Gif - sur - Yvette, France

$12{ }^{3}$ Key Laboratory of Cenozoic Geology and Environment, Institute of Geology and

13 Geophysics, Chinese Academy of Sciences, Beijing 100029, China

$14{ }^{4}$ CAS Center for Excellence in Life and Paleoenvironment, Beijing, 100044, China

$15{ }^{5}$ University of Chinese Academy of Sciences, Beijing, 100049, China

$16{ }^{6}$ Department of Atmospheric Science, School of Environmental Studies, China University

17 of Geoscience, Wuhan 430074, China

$18{ }^{7}$ Institute of Tibetan Plateau research, Chinese Academy of Sciences, Beijing, 100101,

19 China

$20 \quad{ }^{8}$ Laboratoire de Météorologie Dynamique, CNRS, Sorbonne Université, Ecole Normale 
21 Supérieure, Ecole Polytechnique, Paris, France

$22{ }^{9}$ Editorial Office of Advances in Atmospheric Sciences, Institute of Atmospheric Physics,

23 Chinese Academy of Sciences, Beijing 100029, China

$24{ }^{10}$ CAS Center for Excellence in Tibetan Plateau Earth Sciences, Chinese Academy of

25 Sciences (CAS), Beijing, 100101, China

26 Corresponding author: Yong Sun (sunyong@mail.iap.ac.cn)

\section{Key points:}

28 - Quantitative data-model comparison shows an overall increase except for local 29 decease in EASM precipitation during the MH.

30 - Dynamic enhancement of horizontal moisture advection increases EASM precipitation

31 in both proxy records and simulations.

32 - The thermodynamic increase of horizontal moisture advection in precipitation in both

33 the proxy records and simulations is reduced by a cloud cooling effect.

34 - Decreasing precipitation in both the proxy records and models can be largely explained

35 by the coupled thermodynamic and dynamic effects on horizontal moisture advection 


\section{Abstract}

37 The mid-Holocene $(\mathrm{MH} ; 6 \mathrm{ka})$ is one of the benchmark periods for the Paleoclimate 38 Modeling Intercomparison Project (PMIP) and provides a unique opportunity to study 39 monsoon dynamics and orbital forcing (i.e., mostly precession) that differ significantly

40 from the present day. We conducted a data-model comparison along with a dynamic 41 analysis to investigate monsoonal (i.e., East Asian summer monsoon; EASM) precipitation 42 changes over East Asia during the MH. We used the three phases of the PMIP simulations

43 for the $\mathrm{MH}$, and quantitatively compared the model results with pollen-based climate 44 records. The data-model comparison shows an overall increase in precipitation, except for 45 a local decrease in EASM precipitation during the MH. Decomposition of the moisture 46 budget into thermodynamic, dynamic components and co-variations in both allowed us to 47 assess the relative role of thermodynamic and dynamic components in controlling EASM 48 precipitation during the $\mathrm{MH}$, and to investigate the precipitation changes obtained from 49 pollen records in terms of physical processes. We show that the dynamic effect, rather than 50 the thermodynamic effect, is the dominant control in increased EASM precipitation during

51 the $\mathrm{MH}$ in both the proxy records and models. The dynamic increase in precipitation results

52 mainly from the enhancement of horizontal monsoonal moisture transport that is caused by

53 intensified stationary eddy horizontal circulation over East Asia. In addition, a cloud 54 cooling effect reduced the thermodynamic contribution to the increase in EASM 55 precipitation during the $\mathrm{MH}$.

56 Keywords: Mid-Holocene, Monsoon precipitation, Water vapor budget, Thermodynamic 57 effect, Dynamic effect, Cloud cooling effect 


\section{Introduction}

60 The mid-Holocene ( $\mathrm{MH} ; \mathrm{ca} .6 \mathrm{ka})$ is part of the current interglacial period. This period was

61 characterized by a large change in precession, which led to an enhanced seasonal cycle,

62 whereas greenhouse gases (GHGs) were similar to pre-industrial (PI) levels and continental

63 configurations were almost identical to the present day. Therefore, the $\mathrm{MH}$ is an ideal

64 period for studying the orbital-forcing of Earth's climate (Steig 1999; Shin et al. 2006).

65 Paleoclimatic reconstructions and simulations based on the Paleoclimate Modeling

66 Intercomparison Project (PMIP) protocols are important approaches for investigating

67 large-scale $\mathrm{MH}$ climate features and the mechanisms driving climate changes. In general,

68 data-model comparisons have shown similar annual mean monsoonal precipitation

69 changes during the MH compared with the PI period (COHMAP Members 1988;

70 Braconnot et al. 2012; Zhao and Harrison 2012; Jiang et al. 2015; Jiang et al. 2019; Lin et

71 al. 2019; D’Agostino et al. 2019, 2020). Solar radiation increases (decreases) in the boreal

72 (austral) summer acted as the main driver of strengthening (weakening) of the Northern

73 (Southern) Hemisphere monsoon in the MH (Joussaume et al. 1999; Zhao and Harrison

74 2012; Jiang et al. 2015; Brierley et al. 2020). In addition to the direct response to solar

75 forcing, regional monsoonal precipitation changes are also influenced by feedback from

76 vegetation expansion, dust reduction (Patricola and Cook 2007; Pausata et al. 2016;

77 Hopcroft and Valdes 2019; Piao et al. 2020), and oceanic processes (Liu et al. 2004; Zhao

78 et al. 2005; Zhao and Harrison 2012). The "Green Sahara" involved the northward

79 extension of vegetation in North Africa during the $\mathrm{MH}$, which increased Northern

80 Hemisphere on-land monsoonal precipitation (Sun et al. 2019) and shifted the East Asian

81 summer monsoon (EASM) northward (Piao et al. 2020). The vegetated Sahara induced 
82 changes in Walker and Hadley circulations, enhanced the western Pacific subtropical high

83 (WPSH), and strengthened the EASM (Piao et al. 2020).

84 An increasing number of studies have used dynamic diagnostics to improve our

85 understanding of regional rainfall processes during the $\mathrm{MH}$. Using a moisture budget

86 analysis, D'Agostino et al. (2019) examined the impact of thermodynamic and dynamic

87 components on the Northern Hemisphere monsoon response to MH orbital forcing, and

88 found that dynamic processes were the dominant contributor to increased monsoon

89 precipitation in the $\mathrm{MH}$. This increase in precipitation due to the dynamic effect can largely

90 be explained by enhanced vertical motion due to local diabatic heating of the atmospheric

91 column (D'Agostino et al. 2019). Although D'Agostino et al. (2019) did not consider the

92 EASM due to the hybrid nature of the tropical and subtropical monsoon with impacts from

93 mid and high-latitudes (Ding and Chan 2005), the findings were found to be valid for the

94 EASM by Wang et al. (2020). However, it remains unclear why the thermodynamic

95 contribution to monsoon precipitation changes during the $\mathrm{MH}$ was weak. In addition to the

96 key role of vertical moisture advection (Wang et al. 2020), it remains to be determined

97 whether a dynamic increase in MH precipitation can be achieved through enhancement of

98 horizontal monsoon circulation. In addition, the simulated EASM precipitation changes

99 during the MH have not been validated by proxy records. Therefore, the response of the

100 EASM climate to orbital forcing during the MH is not fully understood.

101 In this study, we first conducted a quantitative data-model comparison of EASM

102 precipitation changes during the $\mathrm{MH}$. We then reconciled the data-model comparison by

103 comparing decomposed physical processes that affect the moisture budget. 


\section{$106 \quad$ 2.1 Three phases of PMIP simulations for MH climate}

107 MH simulations using the three phases of PMIP (PMIP2, PMIP3, and PMIP4) were used

108 to provide a dynamic understanding of EASM precipitation variations at orbital timescales.

109 The same orbital parameter configurations (eccentricity $=0.018682$; obliquity $=24.105^{\circ}$;

110 angular precession $=0.87^{\circ}$ ) were used in all three PMIP phases for the MH, but in the PI

111 runs slight differences in the reference periods were chosen for the three PMIP phases

112 (Braconnot et al. 2007, 2012; Otto-Bliesner et al. 2017). Orbital forcing of the PI runs in

113 PMIP2 and PMIP3 was set to 1950 , and the orbital parameters in 1850 were applied to the

114 PI run in PMIP4.

115 In addition, there are two differences in GHG concentrations for PMIP4 compared with 116 PMIP2 and PMIP3: (1) the same trace gas concentrations $\left(\mathrm{CO}_{2}=280 \mathrm{ppm} ; \mathrm{N}_{2} \mathrm{O}=270 \mathrm{ppb}\right)$

117 were used for the MH and PI periods under the PMIP2 and PMIP3 protocols, except for a

118 reduction in $\mathrm{CH}_{4}$ (from $760 \mathrm{ppb}$ in the PI period to $650 \mathrm{ppb}$ in the MH); (2) PMIP4 utilized

119 different GHG concentrations for the PI period $\left(\mathrm{CO}_{2}=284.3 \mathrm{ppm} ; \mathrm{CH}_{4}=808.2 \mathrm{ppb} ; \mathrm{N}_{2} \mathrm{O}\right.$

$120=273.0 \mathrm{ppb})$ and $\mathrm{MH}\left(\mathrm{CO}_{2}=264.4 \mathrm{ppm} ; \mathrm{CH}_{4}=597 \mathrm{ppb} ; \mathrm{N}_{2} \mathrm{O}=262.0 \mathrm{ppb}\right)$ simulations.

121 In addition, the solar constant used by PMIP4 $\left(1360.7 \mathrm{~W} / \mathrm{m}^{2}\right)$ is lower than that used in

122 PMIP2 and PMIP3 (1365 W/m²). More details of the PMIP models used for the MH

123 simulations are presented in Tables S1 and S2. In brief, the climate change during the $\mathrm{MH}$

124 obtained from PMIP simulations is broadly consistent with theory and observations,

125 including increased summer warming of the Northern Hemisphere and associated shifts in

126 tropical rainfall. Biases in the magnitude and sign of regional responses are similar in 
127 PMIP2, PMIP3, and PMIP4, despite the improvement of the models in complexity and

128 resolution (Braconnot et al. 2012; Brierley et al. 2020).

129 In this study, we generally present findings based on the multi-model ensembles (MMEs)

130 mean of PMIP3 and PMIP4, except for Fig. 1, which shows results from the MMEs of all

131 three PMIP phases, because all three phases of PMIP yield similar surface climate

132 simulations for East Asia during the MH. The individual MME results for each PMIP phase

133 are given in the online Supplementary Materials.

\section{$135 \quad 2.2$ Methodology}

\section{$136 \quad$ 2.2.1 Moisture budget}

137 The water vapor budget equation was used to constrain the physical processes that control 138 the monsoonal precipitation variations on orbital timescales. The time-mean column139 integrated moisture budget can be expressed as:

$$
P=E-\left\langle\omega \partial_{P} q\right\rangle-\left\langle\vec{V}_{H} \cdot \nabla q\right\rangle+\operatorname{Res}
$$

141 where $P$ is the precipitation, $E$ is the evaporation, $\omega$ is the vertical velocity at a constant 142 pressure coordinate, $q$ is the atmospheric specific humidity, $V_{H}$ is the horizontal wind 143 velocity, and Res is a residual term including transient eddy influences and their potential 144 role in shaping EASM precipitation that was not addressed due to the unavailability of 145 daily output from most PMIP models. By designating the column mass integrals with angle

146 brackets, $<\cdot\rangle=\int_{0}^{p_{s}} \cdot d p / g$, where $P_{s}$ is the surface pressure (Chou and Lan 2012). The 147 difference in each term in Eq. 1 between the MH and PI period can be written as follows:

$$
\delta P=\delta E-\delta\left\langle\omega \partial_{P} q\right\rangle-\delta\left\langle\vec{V}_{H} \cdot \nabla q\right\rangle+\delta R e s
$$

149 To assess the relative importance of moisture content and atmospheric circulation changes 
150 on moisture transport, variations in two advection terms were further decomposed into

151 linear contributions from the thermodynamic component (TC) and dynamic component

152 (DC), and non-linear contribution from the quadratic term (NL). TC was calculated as an

153 advective variation caused by changes in specific humidity with a fixed atmospheric

154 circulation, and DC is represented by changes in atmospheric circulation at a constant

155 specific humidity. NL was obtained from simultaneous changes in both atmospheric

156 circulation and specific humidity (Seager et al. 2010). The relationships between TC, DC,

157 and NL and changes in $-\left\langle\vec{V}_{H} \cdot \nabla q\right\rangle$ can be expressed as:

$$
\begin{aligned}
& \mathrm{TC}=-\left\langle\overline{\vec{V}}_{H} \cdot \nabla \delta q\right\rangle=-\int_{0}^{P_{S}} \overline{\vec{V}}_{H} \cdot \nabla \delta q d p \\
& \mathrm{DC}=-\left\langle\delta \vec{V}_{H} \cdot \nabla \bar{q}\right\rangle=-\int_{0}^{P_{S}} \delta \vec{V}_{H} \cdot \nabla \bar{q} d p \\
& \mathrm{NL}=-\left\langle\delta \vec{V}_{H} \cdot \nabla \delta q\right\rangle=-\int_{0}^{P_{S}} \delta \vec{V}_{H} \cdot \nabla \delta q d p
\end{aligned}
$$

161 Similarly, the decomposition of changes in $-\left\langle\omega \partial_{P} q\right\rangle$ into TC, DC, and NL can be written 162 as:

$$
\mathrm{TC}=-\left\langle\bar{\omega} \partial_{P} \delta q\right\rangle=-\int_{0}^{P_{s}} \bar{\omega} \partial_{P} \delta q d p
$$

\subsubsection{Climate feedback response analysis method}

168 The climate feedback response analysis method (CFRAM) was used to quantify the relative contributions of nine separate processes on surface temperature differences between the MH and PI period. The CFRAM formula is (Cai and Lu 2009; Lu and Cai 2009): 


$$
\begin{aligned}
\Delta \mathbf{T}_{\mathrm{MH}-\mathrm{PI}} & =\left(\frac{\partial \mathbf{R}}{\partial \mathbf{T}}\right)^{-1}\left(\Delta \mathbf{S}^{\mathrm{SI}}+\Delta \mathbf{S}^{\alpha}+\Delta(\mathbf{S}-\mathbf{R})^{\mathrm{Wv}}+\Delta(\mathbf{S}-\mathbf{R})^{\mathrm{cld}}+\Delta(\mathbf{S}-\mathbf{R})^{\mathrm{CH}_{4}}+\Delta \mathbf{Q}^{\mathrm{SH}}+\Delta \mathbf{Q}^{\mathrm{LH}}\right. \\
& \left.+\Delta \mathbf{Q}^{\mathrm{AHT}}+\Delta \mathbf{Q}^{\text {Surface_dynamics }}\right)
\end{aligned}
$$

173 where $\left(\frac{\partial \mathbf{R}}{\partial \mathbf{T}}\right)$ is the Planck feedback matrix and the superscripts SI, $\alpha, w v$, cld, and $\mathrm{CH}_{4}$

174 denote the surface temperature changes induced by solar insolation, surface albedo, water 175 vapor, cloud, and methane, respectively. The superscripts SH, LH, AHT, and

176 Surface_dynamics are the surface temperature changes due to sensible heat, latent heat, 177 atmospheric heat transport, and surface dynamics. The advantage of this method is that it 178 allows the actual processes that are responsible for the reduced thermodynamic increase in 179 monsoonal precipitation to be distinguished (Fig. 2c and Figure 6e).

\section{$181 \quad$ 2.2.3 EASM domains}

182 The EASM domains of this study follow the definition of Wang et al. (2012). The two 183 required conditions are: (1) the annual range of precipitation rates (defined as local summer 184 minus local winter) is $>2 \mathrm{~mm} /$ day; (2) the local summer precipitation is $>55 \%$ of total 185 annual rainfall. The local summer includes May-June-July-August-September and local 186 winter includes November-December-January-February-March. Given the inter-model 187 spread of EASM domains across the MH and PI simulations, and slight differences in the 188 EASM domains between the MH and PI periods, the results were averaged over the EASM 189 domain of each model. 


\subsection{Quantitative data-model comparison over the EASM domain}

192 Figure 1 shows the surface air temperature (SAT) and precipitation (PRECIP) changes

193 during the MH compared with the PI period. SAT changes during the MH are non-uniform

194 across the EASM domain (Fig. 1a). This is reflected by southern cooling (south of $30^{\circ} \mathrm{N}$ )

195 and northern warming (north of $30^{\circ} \mathrm{N}$; Fig. 1a). Consequently, these variations in SAT

196 changes are associated with a reduction in meridional thermal contrast over the monsoonal

197 domain, and its potential effects on the MH monsoonal precipitation are addressed in

198 section 3.3.1.

199 There is an overall increase in EASM precipitation during the $\mathrm{MH}$, except for a decrease

200 in a few parts of the monsoon area in both the proxy data and simulations (Figs 1b-c and

201 S1). Out of 147 pollen-based reconstruction sites, 126 show an EASM precipitation

202 increase under the warm $\mathrm{MH}$ conditions (Fig. 1b), and the remaining 21 sites show a

203 precipitation decrease (Fig. 1b). The PMIP models generate wetter (drier) MH than PI

204 conditions over most (few) parts of the EASM domain (Figs 1c and S1). However, there

205 are distinct regions where the precipitation decreases during the MH (Figs 1b-c and S1),

206 which are mostly in northern China. Decreases in the modeled precipitation are confined

207 to regions of the eastern Tibetan Plateau.

208 We now use dynamic diagnostics to further examine the underlying cause of the spatial 209 inhomogeneity in simulated precipitation, and thus reconcile the data-model comparison.

2113.2 Reconciling the data-model comparison by decomposition of the water vapor 212 budget 
213 3.2.1 Decomposing the physical processes involved in the simulated precipitation

214 changes

215 An area-averaged moisture budget analysis was first undertaken over the EASM domain

216 for the PI and MH periods (Fig. 2a). Evaporation and vertical moisture advection were

217 identified as being the dominant contributors to the mean summer precipitation over East

218 Asia in the PI and MH periods, whereas the horizontal moisture advection and residual

219 terms were less important. There are large inter-model variations for each moisture budget

220 term (Figs $2 \mathrm{~b}$ and S2a). To reveal the potential mechanisms for this range, and quantify the

221 relative roles of horizontal and vertical moisture transport in controlling precipitation

222 changes, further decomposition of the two moisture advection terms was carried out (Figs

223 2c and S2b). Despite the inter-model variations in each advection term, the signs of each

224 term are largely consistent for all models (Figs 2c and S2b). For example, the three

225 decomposed terms for total moisture advection (i.e., the sum of horizontal and vertical

226 moisture advection) have a positive DC value, negative NL value, and negligible TC value

227 compared with DC and NL. A positive DC value increases precipitation and a negative NL

228 value leads to a precipitation decrease. There are distinct values for each decomposed

229 process for the horizontal and vertical moisture advection (Fig. 2c). DC (NL) has an

230 overwhelming effect on the precipitation increase (decrease), which is due mainly to

231 strengthening (weakening) of the horizontal moisture advection. However, a much weaker

232 precipitation increase is caused by the TC of the horizontal moisture advection. In summary,

233 the horizontal moisture advection has a dominant role in the total moisture advection.

234

235 3.2.2 Decoding the physical representation of pollen-based precipitation records 
236 Decomposition of the two moisture advection types was used to understand the physical

237 processes involved in pollen-based precipitation records. Figure 3 shows a quantitative

238 comparison of the pollen-based precipitation record with the three decomposed processes

239 from the two moisture advection types (Fig. 3). The increase in precipitation from the proxy

240 records are due mainly to intensified horizontal moisture advection (Fig. 3b). For example,

241106 of 126 proxy records show a precipitation increase that can be explained by dynamic

242 enhancement of horizontal moisture advection (Fig. 3b). The remaining 20 proxy records

243 show a precipitation increase that can be attributed to a weak increase in the TC of

244 horizontal moisture advection (Fig. 3e). This is in good agreement with the limited role of

245 the TC in increasing precipitation (Fig. 2c). In contrast, a decrease in precipitation in 21

246 proxy records can be explained by the weakened NL of the horizontal moisture advection

247 (Fig. 3h). In general, these results further support our previous modeling, in that horizontal

248 moisture advection is the dominant control on the EASM precipitation changes during the 249 MH.

\section{$251 \quad 3.3 \quad$ Physics of the moisture budget decomposition}

252 The moisture budget decomposition provides new insights into the data-model comparison.

253 However, it is unclear what causes the dynamic enhancement of horizontal moisture

254 advection and why the thermodynamic contribution to the precipitation increase is reduced

255 during the MH. In addition, it is unknown whether the water vapor source of this dynamic

256 enhancement has the same pathway as the EASM precipitation. Therefore, the physics

257 underlying the thermodynamic and dynamic processes of horizontal moisture advection

258 are further addressed in this section. 


\section{$260 \quad$ 3.3.1 Mechanisms of dynamic control on the precipitation}

261 The EASM domain and surrounding regions are dominated by stationary eddy horizontal 262 circulation anomalies, as manifested by an anomalous cyclone confined to south of $30^{\circ} \mathrm{N}$

263 and a strong anticyclone to the north (Figs S3 and $4 a-b)$. The regional horizontal moisture 264 advection is enhanced by the cyclonic control over the EASM domain, and thus leads to a 265 dynamic increase in EASM precipitation during the MH (Fig. 4b). Prominent easterly 266 anomalies are observed between the cyclone and anticyclone $\left(30^{\circ}-45^{\circ} \mathrm{N}\right)$. This westerly 267 weakening (i.e., easterly anomalies) can be explained by the thermal wind balance and the 268 reduced meridional thermal contrast (Fig. 1a). In fact, the stationary eddy cyclone and 269 anticyclone that contribute to regional enhancement of horizontal moisture advection over 270 the EASM domain are a key part of the global-scale stationary wave trains, which emanate 271 from anticyclones at Northern Hemisphere mid-latitudes to anticyclones at Southern 272 Hemisphere mid-latitudes (Fig. 4a).

273 In contrast to the dynamic enhancement of horizontal moisture advection, the dynamic 274 decrease of vertical moisture advection resulted in a drier eastern Tibetan Plateau during 275 the MH (Figs 1c, S1, and 3c). This DC decreased the precipitation over the eastern Tibetan 276 Plateau due to the stationary eddy vertical motion in this region. Ascending motion 277 characterizes the western Tibetan Plateau and a descending motion occurs in the eastern 278 Tibetan Plateau (Fig. 4b). In addition to a regional decrease in precipitation, the increase 279 in the stationary eddy vertical motion also intensified the large-scale anti-Hadley 280 circulation that consists of the ascending motion along the Himalaya and the descending 281 motion coinciding with the ascending branch of the Hadley cell (i.e., ITCZ position; Fig. 
4b). As a result, this intensified anti-Hadley circulation resulted in a large-scale decrease

283 in precipitation in the tropics $\left(0^{\circ}-20^{\circ} \mathrm{N}, 60^{\circ}-150^{\circ} \mathrm{E}\right.$; Fig. S1).

\section{3.3.2 Water vapor source during dynamic enhancement of the precipitation}

286 Regional precipitation requires water vapor transport from remote source areas to the 287 regions of precipitation. In mean JJA conditions, cross-equatorial airflow originates in the 288 southern Indian Ocean, which is the main source of water vapor for EASM precipitation 289 (Figs 5a and S4). It is important to consider the sources of water vapor for the dynamic 290 enhancement of EASM precipitation during the MH. There are two major water vapor 291 sources that merge in the tropical Indian Ocean (Fig. 5). One is related to the mid-latitude 292 anticyclone over the northern Pacific Ocean and the other is related to the mid-latitude 293 anticyclone over the northern Atlantic Ocean, which are associated with southward airflow 294 across the Indo-Pacific Warm Pool and North Africa, respectively (Fig. 5). Therefore, the 295 mid-latitude oceans in the Northern Hemisphere are the main source of water vapor supply 296 for the dynamic enhancement of the horizontal moisture transport. This is in agreement 297 with a recent study that showed mid-latitude atmospheric rivers were the dominant water 298 vapor source for EASM precipitation changes during the MH relative to the PI period

299 (Skinner et al. 2020). In contrast, there is a large reduction in the cross-equatorial airflow 300 from the southern Indian Ocean, which is considered the main water vapor supply source 301 for the mean state of EASM precipitation (Fig. 5). This means that the water vapor supply 302 for EASM precipitation changes does not necessarily come from the strongest water vapor 303 pathway for mean EASM precipitation. 


\subsubsection{Reduced thermodynamic role due to cloud cooling}

306 The thermodynamic effect on precipitation is closely related to surface temperature 307 changes. Therefore, quantifying the relative contribution of different processes to surface 308 temperature changes with CFRAM (Cai and Lu 2009; Lu and Cai 2009) enables us to 309 assess which processes affected surface temperature and, in turn, the reduced

310 thermodynamic effect on precipitation. It would be expected that a thermodynamic 311 increase (decrease) in precipitation is associated with surface warming (cooling). As such,

312 the potential physical processes that cool Earth's surface are an underlying cause of the

313 reduced thermodynamic role in the precipitation increase during the $\mathrm{MH}$.

314 By decomposition of the "southern cooling and northern warming" pattern into nine

315 processes (Fig. 1a versus Fig. 6), it was shown that the cloud cooling effect counteracts the

316 main warming effect due to solar insolation, and thus led to this "southern cooling and

317 northern warming" pattern over China (Fig. 6). The remaining five terms generally show

318 either weak surface warming over mainland China (Fig. 6a, d, f, and g) in the absence of

319 surface cooling required to sustain spatial heterogeneity (Fig.1a), or an opposite pattern

320 due to surface dynamic processes affecting the total SAT changes (Fig. 6i). In addition,

321 surface cooling due to ATH and $\mathrm{CH}_{4}$ is so weak that their contribution to the overall SAT

322 changes can be ignored (Fig. $6 \mathrm{c}$ and h). In summary, in addition to their dominant role in

323 the southern cooling and northern warming over East Asia, cloud processes were also

324 dominant in controlling the global surface cooling (not shown). One remaining question is

325 how the surface cooling due to cloudiness affected the monsoon precipitation.

326 Based on the Clausius-Clapeyron relationship, the atmospheric water vapor content

327 decreases with cooling and increases with warming. The damping effects of cloud on 
328 EASM precipitation via regional surface cooling causes water vapor in the atmosphere to

329 decline, and thus decreases the water supply available for precipitation. This is the primary

330 reason for the weak thermodynamic effect during the $\mathrm{MH}$. This result contrasts with the

331 significant thermodynamic effect on EASM precipitation increase/decrease in other

332 warm/cold climates (Sun et al. 2016, 2018, 2021).

333

\section{4. Summary and conclusions}

335 We used proxy data and PMIP simulations to analyze orbital-scale climate variations in the 336 EASM during the $\mathrm{MH}$, when precession was quite different from the present day. Our

337 results revealed distinct monsoonal dynamics at the orbital scale from those projected for

338 future climate (Sun et al. 2018). Horizontal moisture advection controlled EASM

339 precipitation changes during the $\mathrm{MH}$ in both the proxy records and models, and our

340 findings reconcile the regional precipitation changes as determined by proxy records and

341 models. Figure 7 summarizes our key findings, which are:

342 1. A quantitative data-model comparison revealed heterogeneity in the $\mathrm{MH}$ surface

343 climate over the EASM domain. There was an overall increase in EASM precipitation

344 in the proxy data and models, except for a few areas where there was a local decrease

345 in precipitation, which was associated with a reduction in meridional thermal contrast

346 (i.e., the southern cooling and northern warming pattern) over the EASM domain.

347 2. By decomposing the moisture budget, we developed a physical understanding of the 348 spatial heterogeneity of EASM precipitation changes in the proxy data and models.

349 Compared with vertical moisture advection, horizontal moisture advection had a larger

350 role in determining the overall regional increase and local decrease in precipitation. 
351 Dynamic enhancement of horizontal moisture advection can explain the overall 352 increase in precipitation in the simulations and most of the wetter MH proxy records 353 (106 of 126) over the EASM domain. The remaining proxy records of wetter East Asia 354 conditions resulted from a weak thermodynamic contribution to increasing horizontal 355 moisture advection. In contrast, localized decreases in precipitation from the proxy 356 records and models are controlled by two different processes. Drier MH condition in

35721 proxy records reflect a decrease in the NL component of horizontal moisture 358 advection, while a dynamic decrease in vertical moisture advection generated a drier 359 eastern Tibetan Plateau in the simulations.

360 3. Stationary eddy activity is a mechanism that dynamically controls the regional 361 precipitation. The dynamic enhancement of horizontal moisture advection that 362 increased EASM precipitation was due mainly to the intensification of stationary eddy 363 horizontal circulation over the EASM domain during the MH. In contrast, a dynamic 364 decrease in the stationary eddy vertical motion resulted in a drier eastern Tibetan $365 \quad$ Plateau in the $\mathrm{MH}$.

366 4. The cloud cooling effect was the dominant process responsible for surface cooling over 367 the EASM domain, and is thus dominant in producing a southern cooling and northern 368 warming pattern over China. Surface cooling due to cloud processes might have caused 369 a reduction in the thermodynamic contribution to horizontal moisture advection and an 370 increase in precipitation during the $\mathrm{MH}$.

371 5. Mid-latitude oceans in the Northern Hemisphere were the water vapor supply source 372 for the dynamic enhancement of horizontal moisture transport, whereas water vapor 373 transport from the strongest pathway during the mean state of EASM precipitation was 
reduced during the $\mathrm{MH}$.

375

376

377

378

379

380

381

382

383

384 Risi from the Laboratoire de Météorologie Dynamique, Paris, for insightful comments on 385 an earlier version of our manuscript. This research was jointly supported by the National 386 Key Research and Development Program of China (Grant 2018YFA0606003), National 387 Program on Key Basic Research Project of China (Grant 2017YFA0604601), Second 388 Tibetan Plateau Scientific Expedition and Research (STEP) program (Grant 389 2019QZKK0102), National Natural Science Foundation of China (NSFC; Grant 390 41661144009), GOTHAM international cooperative project, National Key Research and 390 41661144009), GOTHAM international cooperative project, National Key Research and 392 and 41572165).

393

\section{Acknowledgements}

We thank the World Climate Research Program's Working Group on Coupled Modeling, which is responsible for CMIP, and the climate modeling groups (Fig. 1) for producing and making available their model outputs. All the simulations are publicly available on a website (https://www.ipcc-data.org/sim/gcm_monthly/AR5/Reference-Archive.html and https://esgf-node.llnl.gov/projects/cmip6/). Pollen-based reconstructions are open access (http://data.lasg.ac.cn/sunyong/pollen-based_reconstructions.pdf). We also thank Camille 2019QZKK0102), National Natural Science Foundation of China (NSFC; Grant 


\section{References}

395 Braconnot P, Otto-Bliesner B, Harrison S, Joussaume S, Peterchmitt J-Y, Abe-Ouchi A, 396 Crucifix M, Driesschaert E, Fichefet T, Hewitt CD, Kageyama M, Kitoh A, Laine A, 397 (2007) Results of PMIP2 coupled simulations of the mid-Holocene and Last Glacial Maximum_part 1: experiments and large-scale features. Clim Past 3(2):261-277

Braconnot P, Harrison SP, Kageyama M, Bartlein PJ, Masson-Delmotte V, Abe-Ouchi A, Otto-Bliesner B, Zhao Y (2012) Evaluation of climate models using palaeoclimatic data. Nat Clim Change 2:417-424

Brierley C, Zhao A, Harrison S, Braconnot P, Williams C, Thornalley D, Shi X, Peterschmitt J-Y, Ohgaito R, Kaufman D, Kageyama M, Hargreaves J, Erb M, EmileGeay J, D'Agostino R, Chandan D, Carré M, Bartlein P, Zheng W, Zhang Z, Zhang Q, Yang H, Volodin E, Tomas R, Routson C, Peltier W, Otto-Bliesner B, Morozova P, McKay N, Lohmann G, Legrande A, Guo C, Cao J, Brady E, Annan J, Abe-Ouchi A(2020) Large-scale features and evaluation of the PMIP4CMIP6 midHolocene simulations. Clim. Past Discuss, https://doi.org/10.5194/cp2019-168

Cai M, Lu JH (2009) A new framework for isolating individual feedback processes in coupled general circulation climate models. Part II: method demonstrations and comparisons. Clim Dyn 32:887-900

Chou C, Lan CW (2012) Changes in the annual range of precipitation under global warming. J Clim 25(1):222-235. https://doi.org/10.1175/JCLI-D-11-00097.1

COHMAP Members (1988) Climatic changes of the last 18,000 years: observations and model simulations. Science 241:1043-1052 
D'Agostino R, Brown J R, Moise A, Nguyen H, Jungclaus J (2020) Contrasting Southern Hemisphere Monsoon Response: MidHolocene Orbital Forcing versus Future Greenhouse Gas-Induced Global Warming. J Clim 33(22), 9595-9613.

D'Agostino R, Bader J, Bordoni S, Ferreira D, Jungclaus J (2019) Northern Hemisphere monsoon response to mid-Holocene orbital forcing and greenhouse gas-induced global warming. Geophys Res Lett 46: 1591- 1601

Ding Y, Chan J (2005) The East Asian summer monsoon: an overview. Meteorol Atmos Phys 89:117-142

Hopcroft P, Valdes P(2019) On the role of dust-climate feedbacks during the midHolocene. Geophys Res Lett 46: 1612- 1621

Jiang D, Tian Z, Lang X (2015) Mid-Holocene global monsoon area and precipitation from PMIP simulations. Clim Dyn 44:2493-2512

Jiang W, Leroy SAG, Yang S, Zhang E, Wang L, Yang X, Rioual P (2019) Synchronous strengthening of the Indian and East Asian monsoons in response to global warming since the last deglaciation. Geophys Res Lett 46:3944-3952

Joussaume S, Taylor K, Braconnot P, Mitchell J, Kutzbach J, Harrison S, Prentice I, Broccoli A, Abe-Ouchi A, Bartlein P, Bonfils C, Dong B, Guiot J, Herterich K, Hewitt C, Jolly D, Kim J, Kislov A, Kitoh A, Loutre M, Masson V, McAvaney B, McFarlane N, de Noblet N, Peltier W, Peterschmitt J-Y, Pollard D, Rind D, Royer J, Schlesinger M, Syktus J, Thompson S, Valdes P, Vettoretti G, Webb R, Wyputta U (1999) Monsoon changes for 6000 years ago: results of 18 simulations from the Palaeoclimate Modelling Intercomparison Project (PMIP). Geophys Res Lett 26:859862 
441 Lin Y, Ramstein G, Wu H, Rani R, Braconnot P, Kageyama M, Li Q, Luo Y, Zhang R,

442 Guo Z (2019) Mid-Holocene climate change over China: model-data discrepancy.

$443 \quad$ Clim Past 15(4): 1223-1249

444 Liu Z, Harrison S, Kutzbach J, Otto-Bliesner B (2004) Global monsoons in the mid$445 \quad$ Holocene and oceanic feedback. Clim Dyn 22: 157-182

446 Liu Z, Zhu J, Rosenthal Y, Zhang X, Otto-Gliesner BL, Timmermann A, Smith RS, 447 Lohmann G, Zheng W, Timm OE (2014) The Holocene temperature conundrum. Proc $448 \quad$ Natl Acad Sci 11:3501-3505

449 Lu J, Cai M (2009) A new framework for isolating individual feedback processes in $450 \quad$ coupled general circulation climate models. Part I: Formulation. Clim Dyn 32: 873$451 \quad 885$

452 Otto-Bliesner BL et al (2017) The PMIP4 contribution to CMIP6 - Part 2: two interglacials, 453 scientific objective and experimental design for Holocene and Last Interglacial $454 \quad$ simulations. Geosci Model Dev 10:3979-4003

455 Patricola C, Cook K (2007) Dynamics of the West African Monsoon under Mid-Holocene 456 Precessional Forcing: Regional Climate Model Simulations. J Clim 20:694-716

457 Pausata F, Messori G, Zhang Q (2016) Impacts of dust reduction on the northward 458 expansion of the African monsoon during the Green Sahara period. Earth Planet Sci $459 \quad$ Lett 434:298-307

460 Piao J, Chen W, Wang L, Pausata F, Zhang Q (2020) Northward extension of the East 461 Asian summer monsoon during the mid-Holocene. Glob Planet Change 184: 462 https://doi.org/10.1016/j.gloplacha.2019.103046 
Shin S-I, Sardeshmukh PD, Webb RS, Oglesby RJ, Barsugli JJ (2006) Understanding the Mid-Holocene Climate. J Clim 19:2801-2817. doi:10.1175/JCLI3733.1

Skinner C, Lora J, Payne A, Poulsen C (2020) Atmospheric river changes shaped mid-

Steig E (1999) Mid-Holocene Climate Change. Science, 286:148-149.

469 Sun W, Wang B, Zhang Q, Pausata F, Chen D, Lu G, Yan M, Ning L, Liu J (2019) Northern Hemisphere land monsoon precipitation increased by the Green Sahara during middle Holocene. Geophys Res Lett 46: 9870-9879

Sun Y, Zhou T, Ramstein G, Contoux C, Zhang Z (2016) Drivers and mechanisms for enhanced summer monsoon precipitation over East Asia during the mid-Pliocene in the IPSL-CM5A. Clim Dyn 46:1437-1457

Sun Y, Ramstein G, Li L, Contoux C, Tan N, Zhou T (2018) Quantifying East Asian summer monsoon dynamics in the ECP4.5 scenario with reference to the midPiacenzian warm period. Geophys Res Lett 45: 12523-12533

Sun Y, Wu H, Kageyama M, Ramstein G, Li L, Tan N, Lin Y, Liu B, Zheng W, Zhang W, Zou L, Zhou T (2021) The contrasting effects of thermodynamic and dynamic processes on East Asian summer monsoon precipitation during the Last Glacial Maximum: a data-model comparison. Clim Dyn 56: 1303-1316

Wang B, Liu J, Kim H, Webster P, Yim S (2012) Recent change of the global monsoon precipitation (1979-2008). Clim Dyn 39:1123-1135 
484 Wang N, Jiang D, Lang X (2020) Mechanisms for Spatially Inhomogeneous Changes in

485 East Asian Summer Monsoon Precipitation during the Mid-Holocene. J Clim 33: $486 \quad 2945-2965$

487 Zhao Y, Braconnot P, Marti O, Harrison S, Hewitt C, Kitoh A, Liu Z, Mikolajewicz U, 488 Otto-Bliesner B, Weber S (2005) A multimodel analysis of role of ocean feedback on 489 the African and Indian monsoon during Mid-Holocene. Clim Dyn 25:777-800

490 Zhao Y, Harrison SP (2012) Mid-Holocene monsoons: a multi-model analysis of the inter491 hemispheric differences in the response to the orbital forcing and ocean feedbacks.

$492 \quad$ Clim Dyn 39:1457-1487

493 
$494 \quad$ Figures

495 

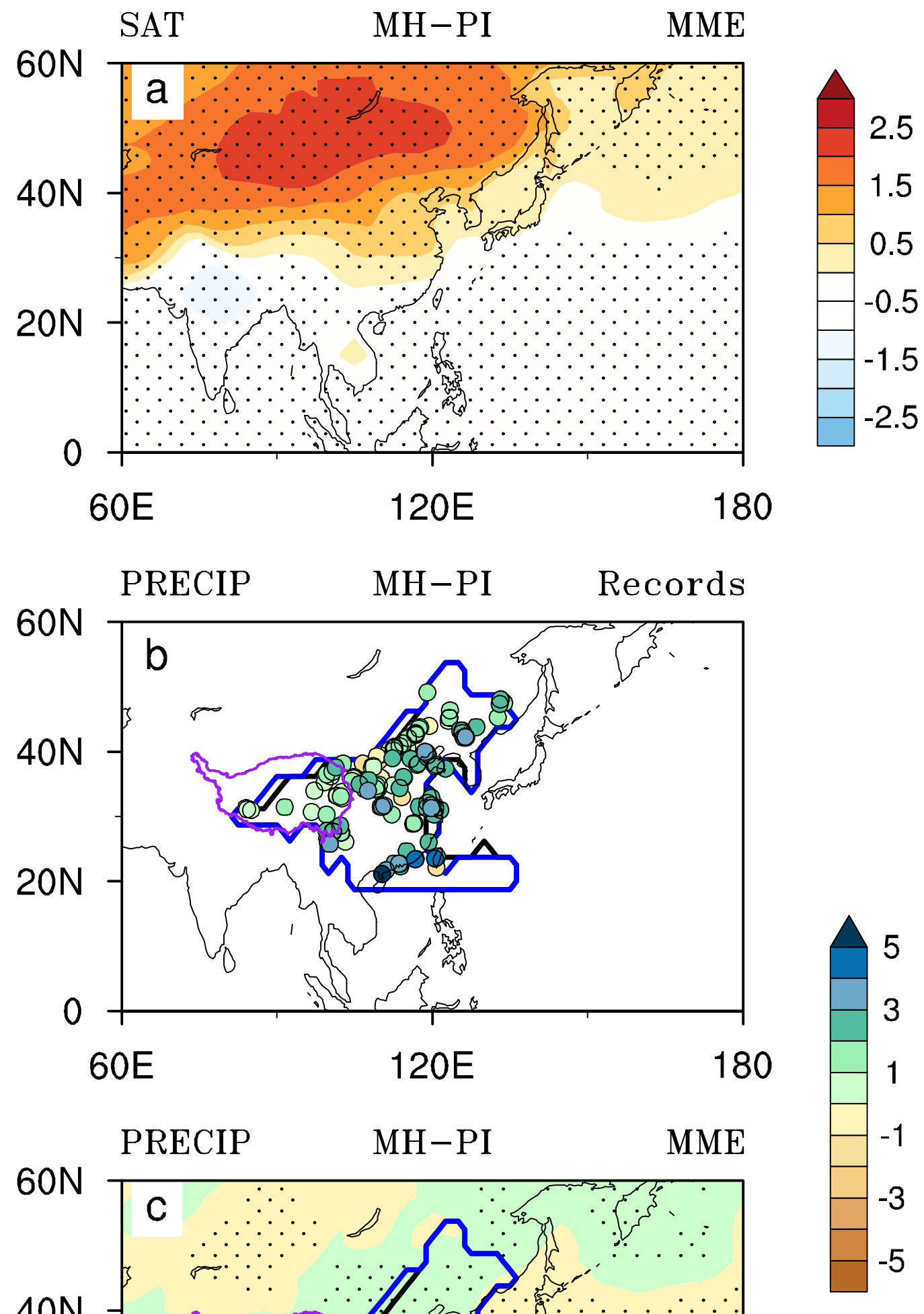

$20 \mathrm{~N}$

0

$60 \mathrm{E}$

$120 \mathrm{E}$

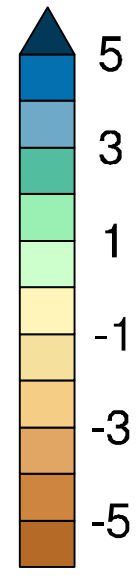


497 Figure 1. Spatial patterns of mean June-July-August (JJA) surface air temperature (SAT 498 in ${ }^{\circ} \mathrm{C}$; top panel) and precipitation (PRECIP in mm/day) changes during the mid-Holocene 499 (MH) compared with pre-industrial (PI) levels derived from pollen-based reconstructions 500 (middle panel) and the multi-model ensemble (MME) of the three PMIP phases (bottom 501 panel). Areas with a significance above the $1 \%$ level are stippled. Black and blue lines on 502 the right panels are the East Asian Summer Monsoon (EASM) domain in the PI period and $503 \mathrm{MH}$, respectively. The purple line outlines the Tibetan Plateau (data source: $504 \mathrm{http} / /$ www.geodoi.ac.cn/weben/doi.aspx? Id=135). Colored circle symbols in (b) use the 505 same color scale as the MME and represent pollen-based reconstructions (147 sites within 506 the EASM domain) for the MH. 

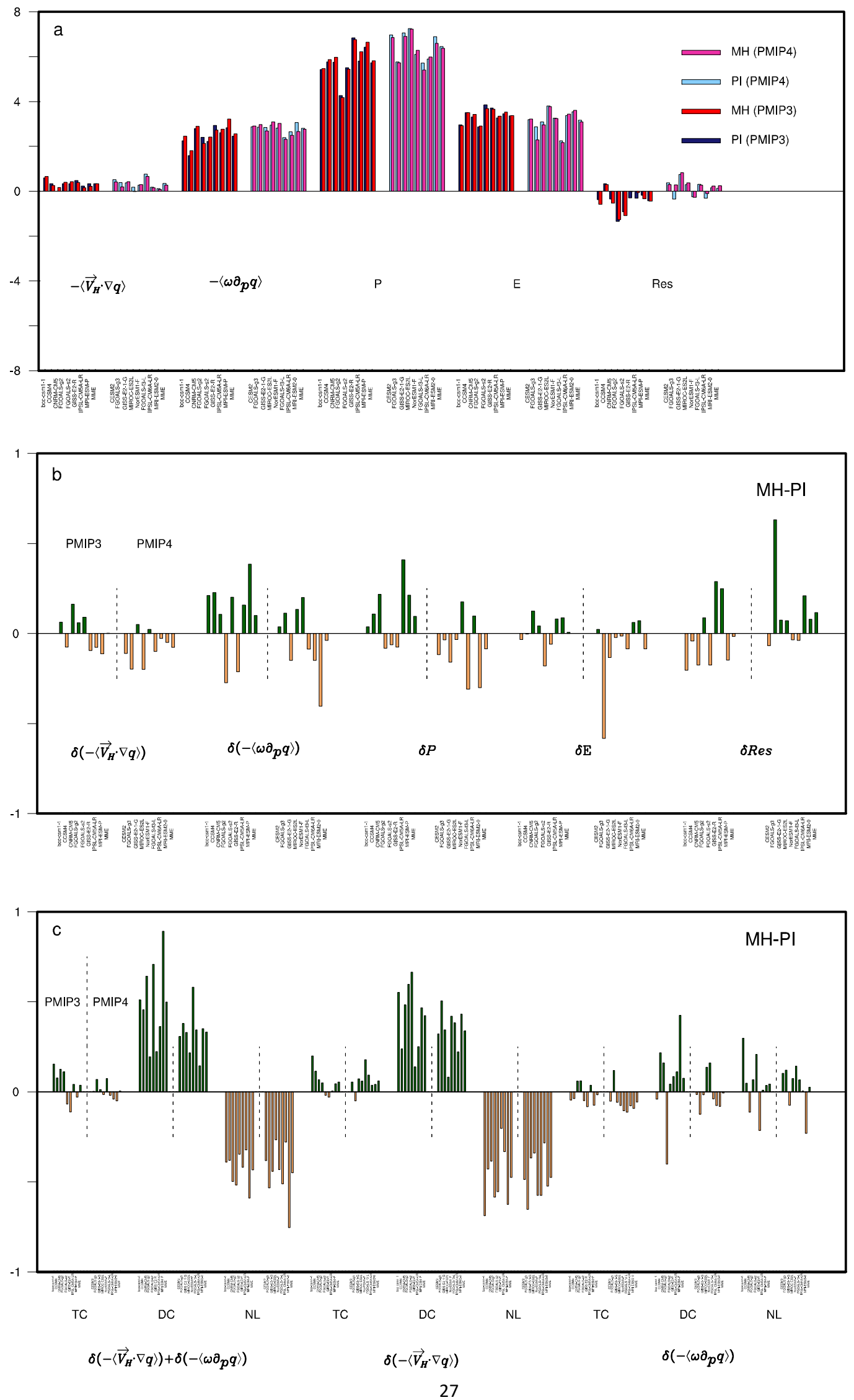
509 Figure 2. Results from the moisture budget equation used to resolve water vapor processes

510 related to mean precipitation for the (a) MH and PI periods and (b) differences between

511 the MH and PI periods. The two difference terms in (b) were decomposed into three

512 processes in (c) to quantify the relative contribution from changes due to specific humidity

513 with fixed atmospheric circulation (thermodynamic component; TC), atmospheric

514 circulation with constant specific humidity (dynamic component; DC), and simultaneous

515 changes in both specific humidity and atmospheric circulation (i.e., non-linear term; NL). 516 

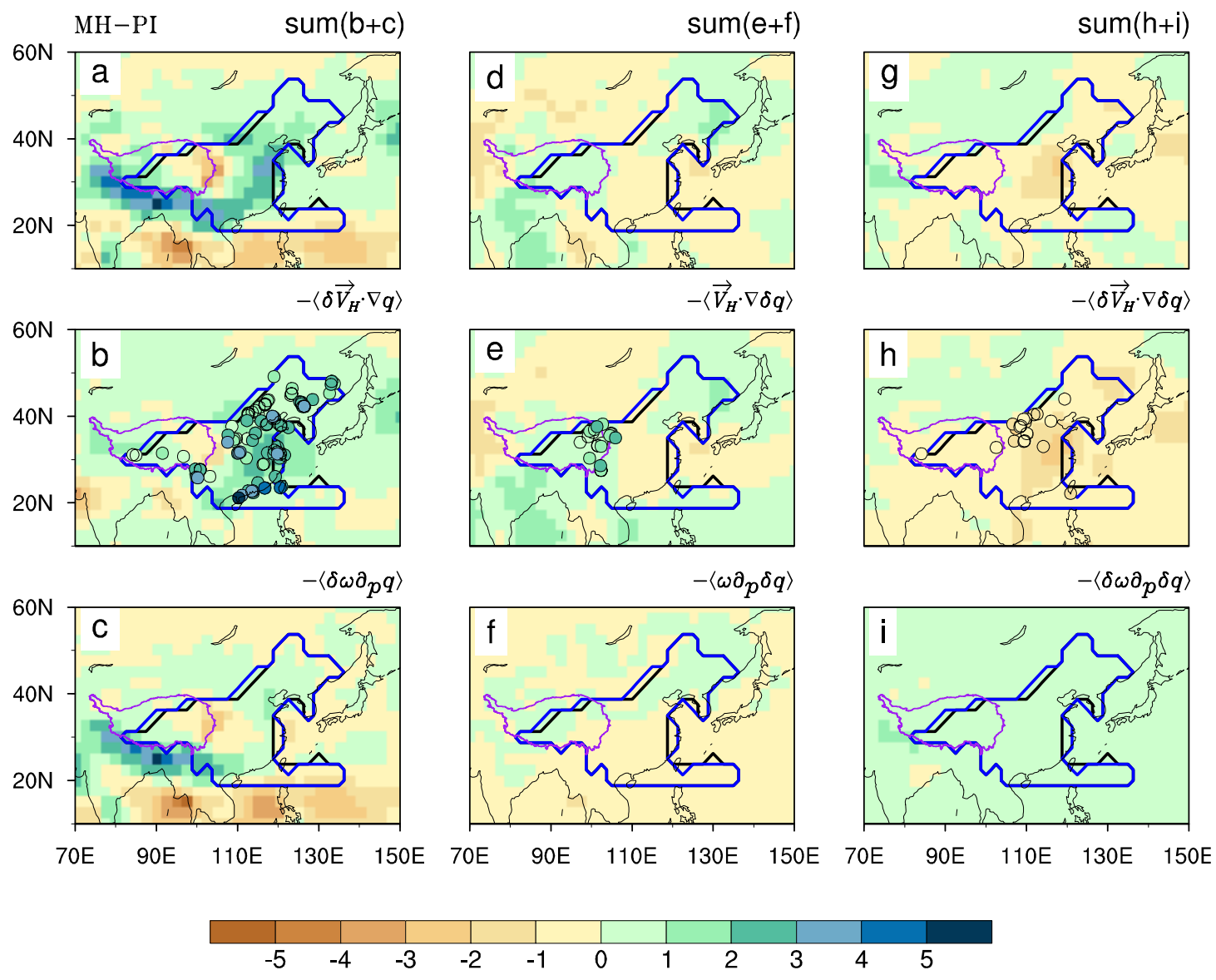

518 Figure 3. Pollen-based precipitation records and spatial patterns of the three decomposed

519 processes for the two moisture advection patterns shown in Fig. 2c. The physical processes

520 (from left to right in each subfigure) are DC, TC, and NL. (c, f, i) Vertical moisture

521 advection. (b, e, h) Horizontal moisture advection. (a, d, g) Sum of the two moisture

522 advections. The 126 green circle symbols (106 in (b) and 20 in (e)) indicate wetter East

523 Asia conditions, and the 21 yellow circle symbols in (h) indicate drier East Asia conditions. 


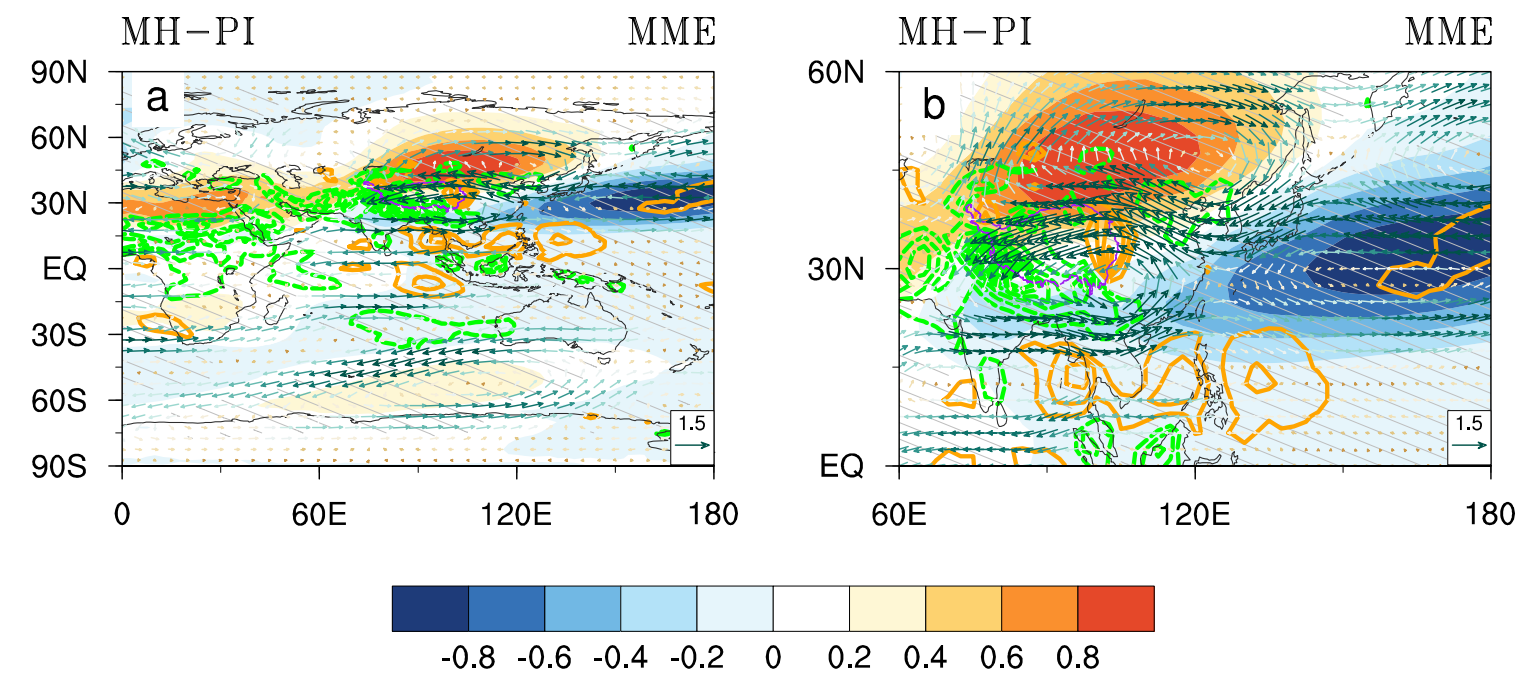

525 Figure 4. (a) Differences between the three vertically integrated variables throughout the

526 troposphere between the $\mathrm{MH}$ and PI periods, which are termed the stationary eddy

527 horizontal circulation (colored vectors; color bar not shown), stationary eddy vertical

528 velocity (contours), and air temperature (shading with color bar). (b) Enlarged view of (a)

529 over the EASM domain. Gray dashed lines are the stationary eddy air temperature above

530 the $1 \%$ level. Positive vertical velocity values indicate descending motion (orange solid

531 contours), and negative values represent ascending motion (green dashed contours). 

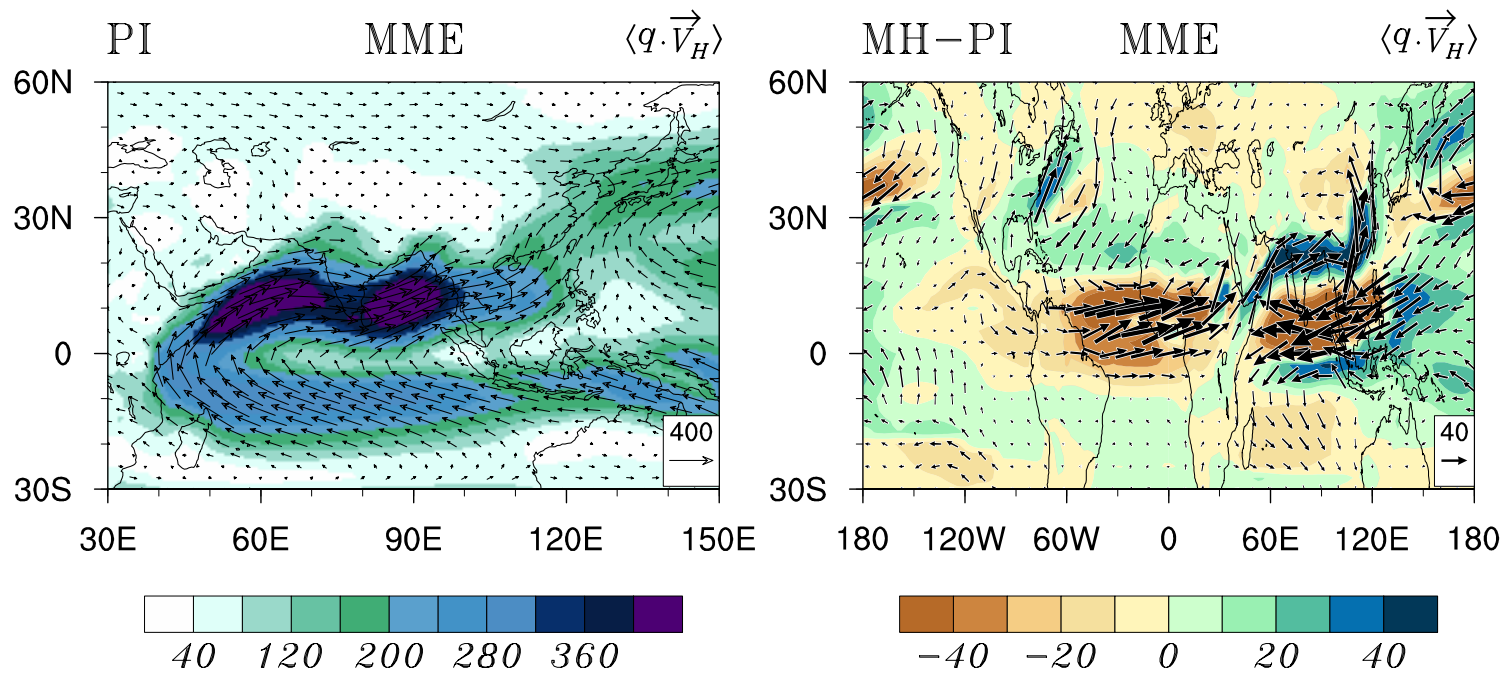

534 Figure 5. Large-scale moisture transport as determined by the vertically integrated

535 moisture flux $\left(\langle q \cdot \vec{V}\rangle\right.$ in $\left.\mathrm{kg} \cdot \mathrm{m}^{-1} \cdot \mathrm{s}^{-1}\right)$ across the whole troposphere in the boreal summer

536 (JJA). (a) Climatology of the PI period. (b) Differences between the MH and PI periods. 

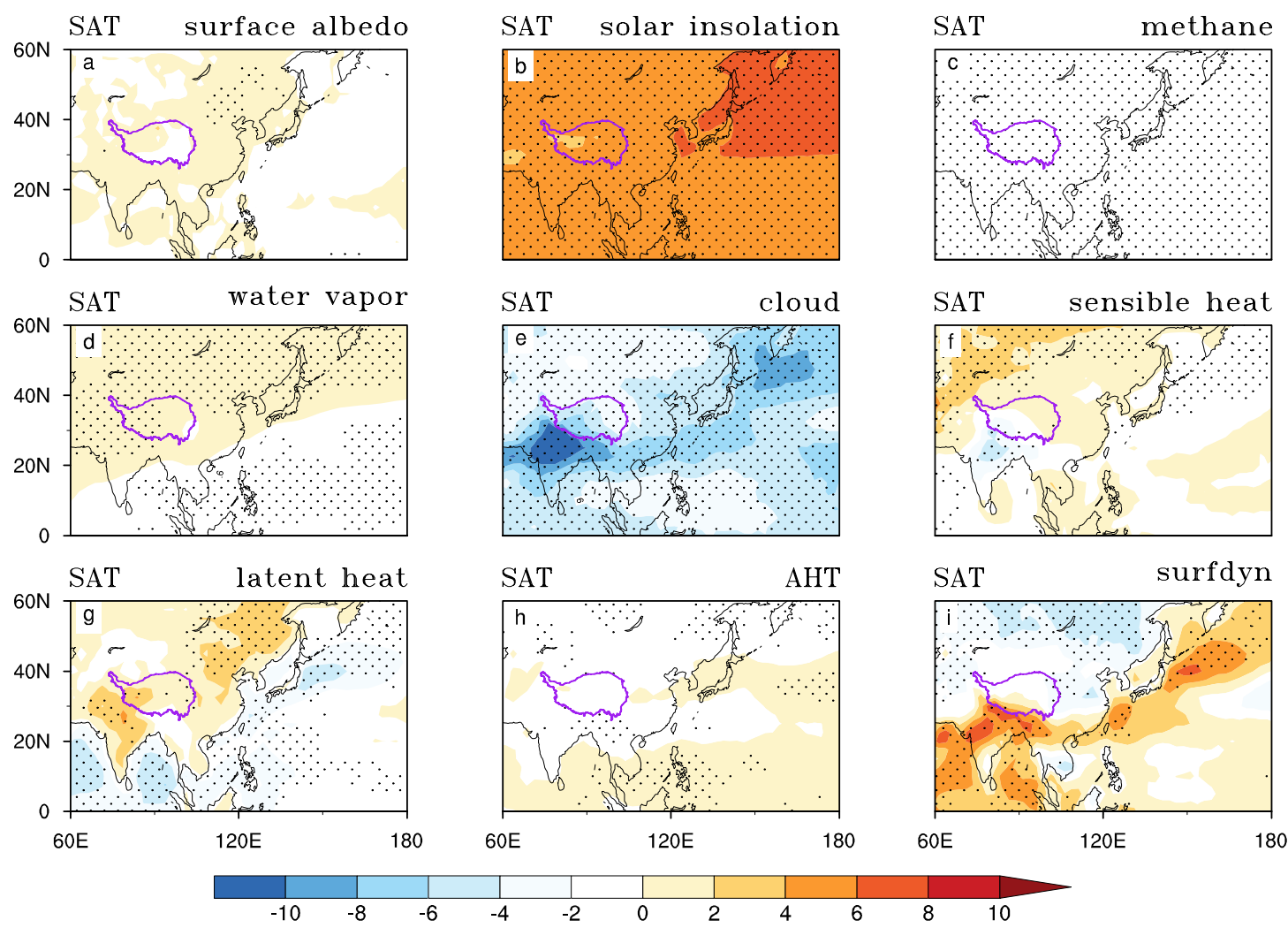

539 Figure 6. CFRAM-based decompositions of SAT changes (in ${ }^{\circ} \mathrm{C}$ ) in the $\mathrm{MH}$ relative to the

540 PI period (as shown in Fig. 1a), as represented by nine processes. AHT and surfdyn in (h-

541 i) are the atmospheric heat transport and surface dynamic processes, respectively. This

542 decomposition was derived from an MME of PMIP3. Stippled areas show that seven of the

543 eight models have the same sign. 


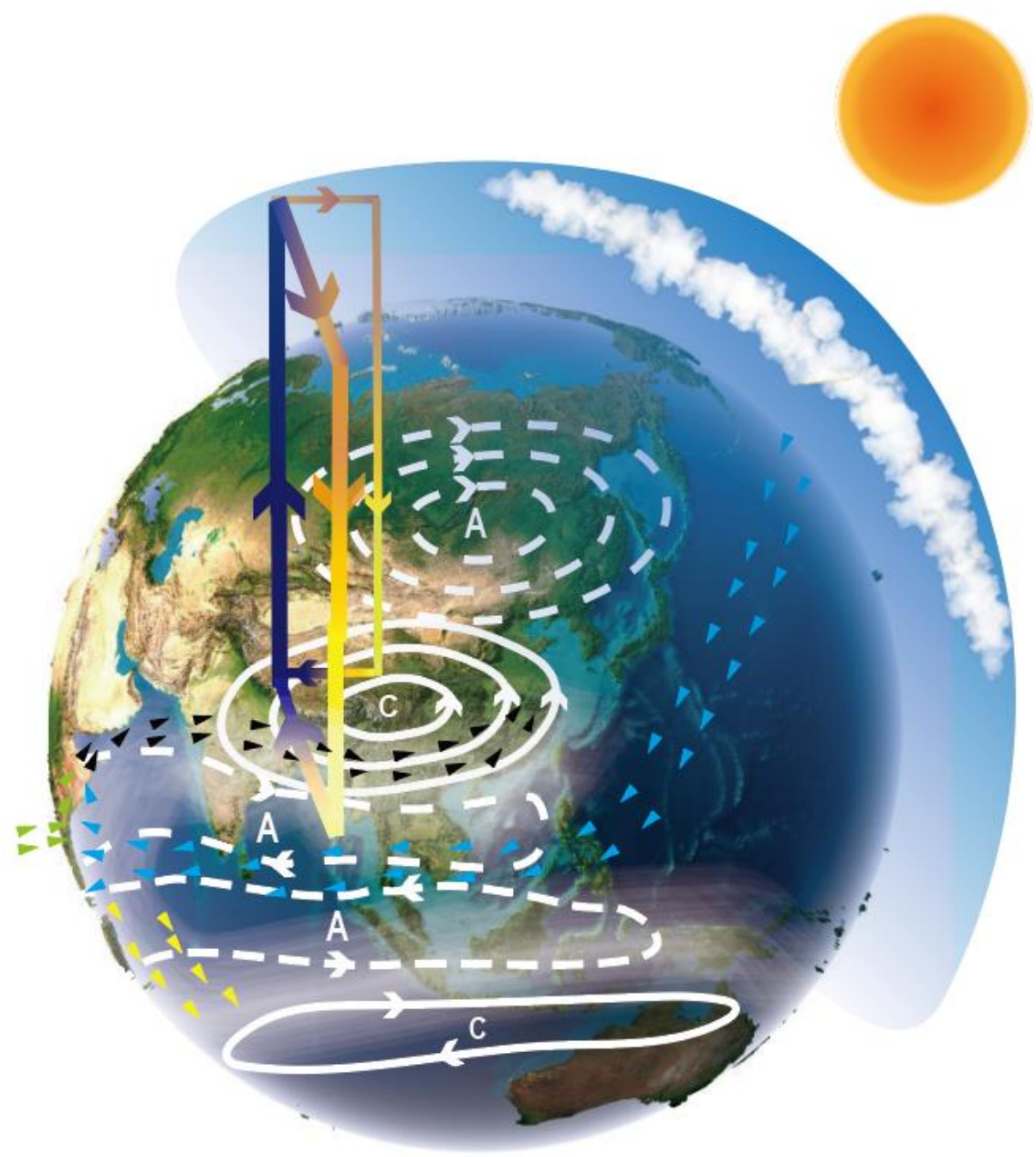

Figure 7. Schematic illustration of the physics underlying monsoon precipitation responses

548 to orbital forcing under $\mathrm{MH}$ climate conditions, including the dynamic strengthening and

549 thermodynamic damping roles in an overall increase in EASM precipitation and a dynamic

550 decrease in precipitation during the $\mathrm{MH}$. Regional dynamic enhancement is part of the

551 global-scale stationary eddy wave trains that consist of stationary eddy cyclones (C) and

552 anticyclones (A) in the Northern and Southern hemispheres. The thermodynamic

553 contribution to the increase in precipitation is reduced by the cloud cooling effect. Vapor

554 sources of intensified moisture transport into the EASM domain are due to intensified

555 stationary eddy circulation (black arrows) from the mid-latitude northern Pacific Ocean 
556 (blue arrows) and northern Atlantic Ocean (green arrows). In contrast, cross-equatorial 557 airflow originates in the southern Indian Ocean which is considered the strongest water 558 vapor supply source for the mean state of EASM precipitation is decreased during the MH 559 (orange arrows). 
Figures
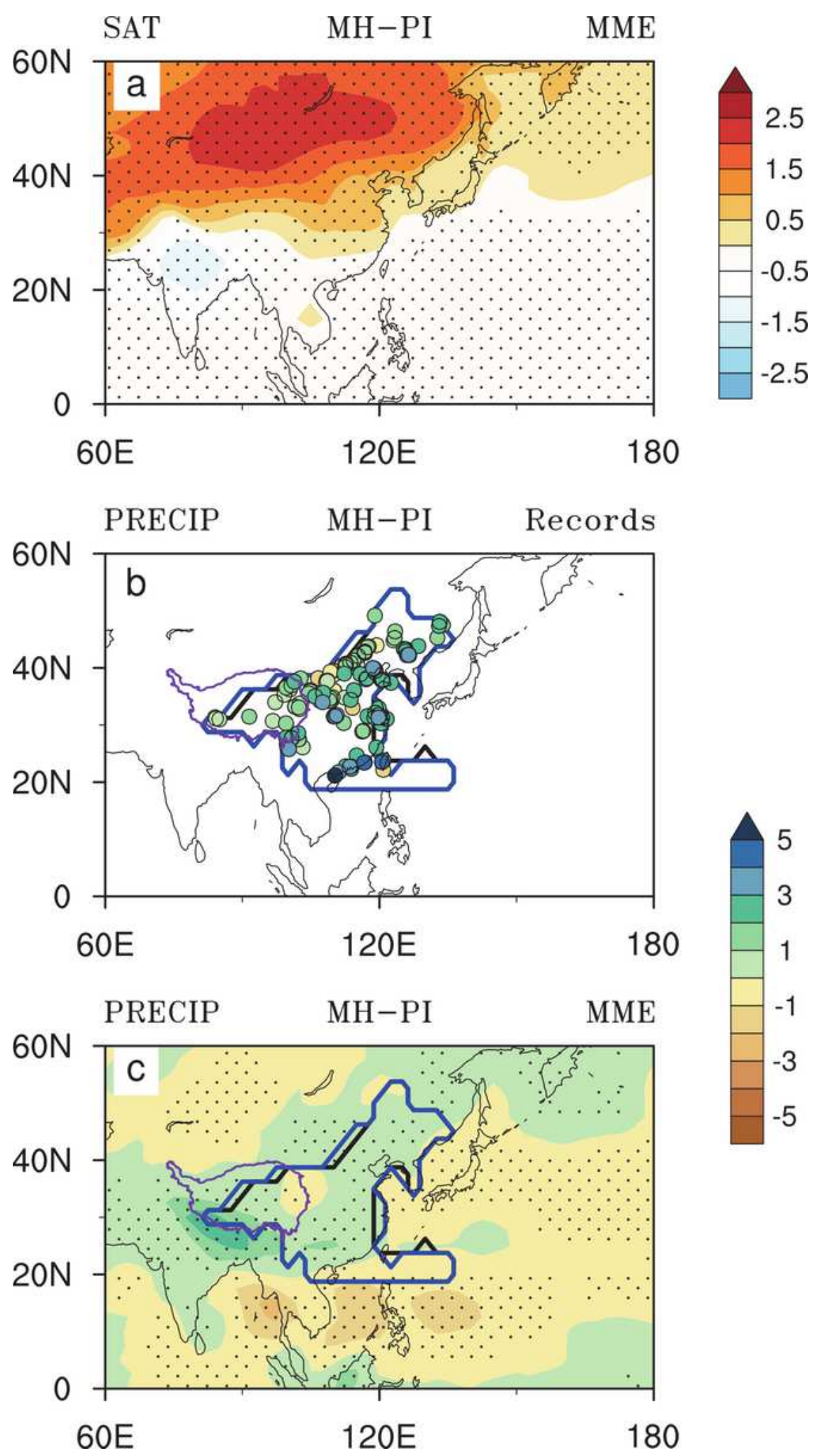

Figure 1

Spatial patterns of mean June-July-August (JJA) surface air temperature (SAT in ${ }^{\circ} \mathrm{C}$; top panel) and precipitation (PRECIP in $\mathrm{mm} /$ day) changes during the mid-Holocene $(\mathrm{MH})$ compared with pre-industrial (PI) levels derived from pollen-based reconstructions (middle panel) and the multi-model ensemble 
(MME) of the three PMIP phases (bottom panel). Areas with a significance above the $1 \%$ level are stippled. Black and blue lines on the right panels are the East Asian Summer Monsoon (EASM) domain in the PI period and $\mathrm{MH}$, respectively. The purple line outlines the Tibetan Plateau (data source:

http://www.geodoi.ac.cn/weben/doi.aspx?ld=135). Colored circle symbols in (b) use the same color scale as the MME and represent pollen-based reconstructions (147 sites within the EASM domain) for the MH. Note: The designations employed and the presentation of the material on this map do not imply the expression of any opinion whatsoever on the part of Research Square concerning the legal status of any country, territory, city or area or of its authorities, or concerning the delimitation of its frontiers or boundaries. This map has been provided by the authors. 

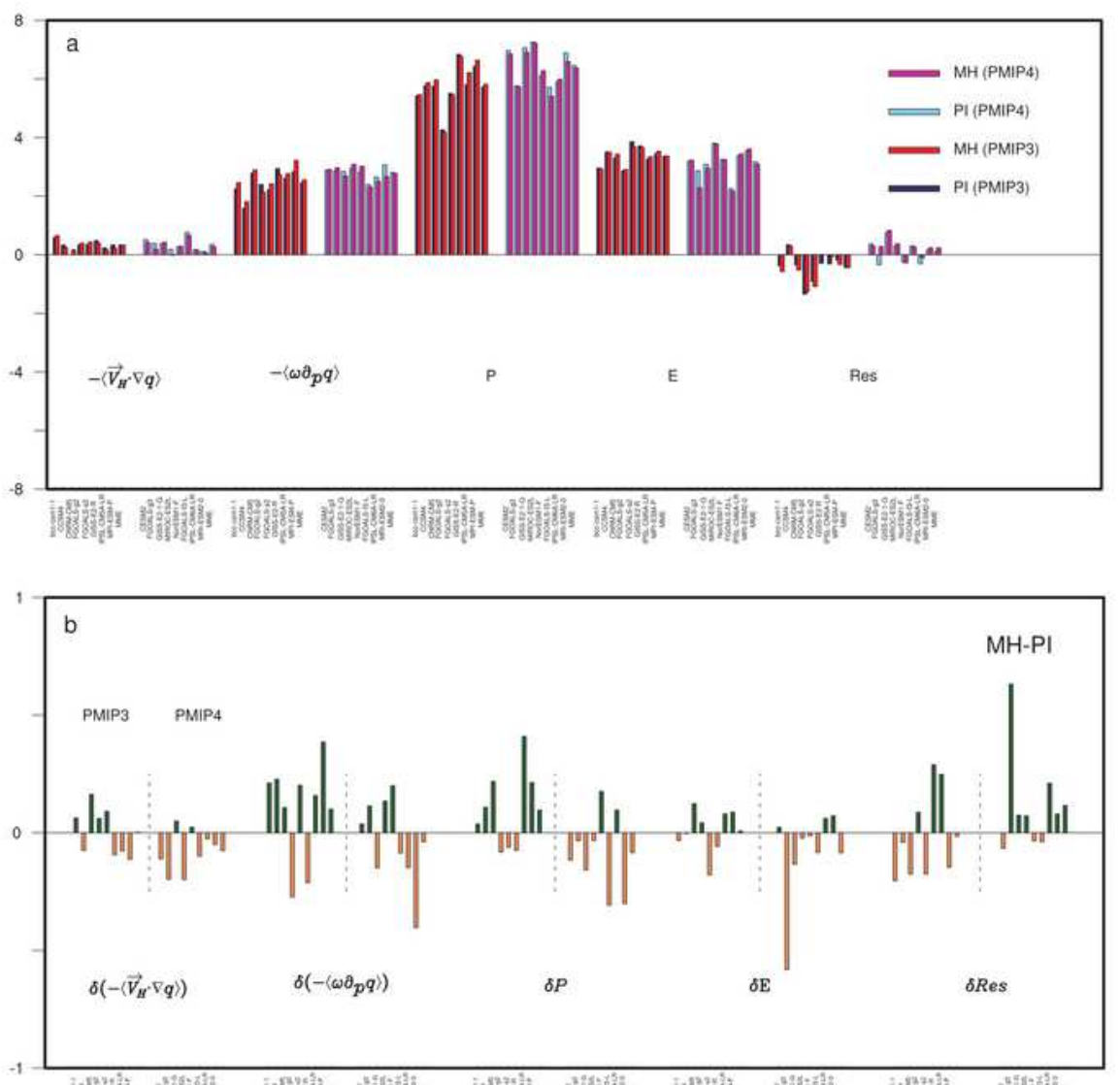

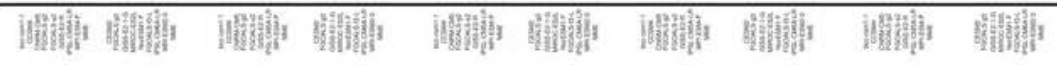

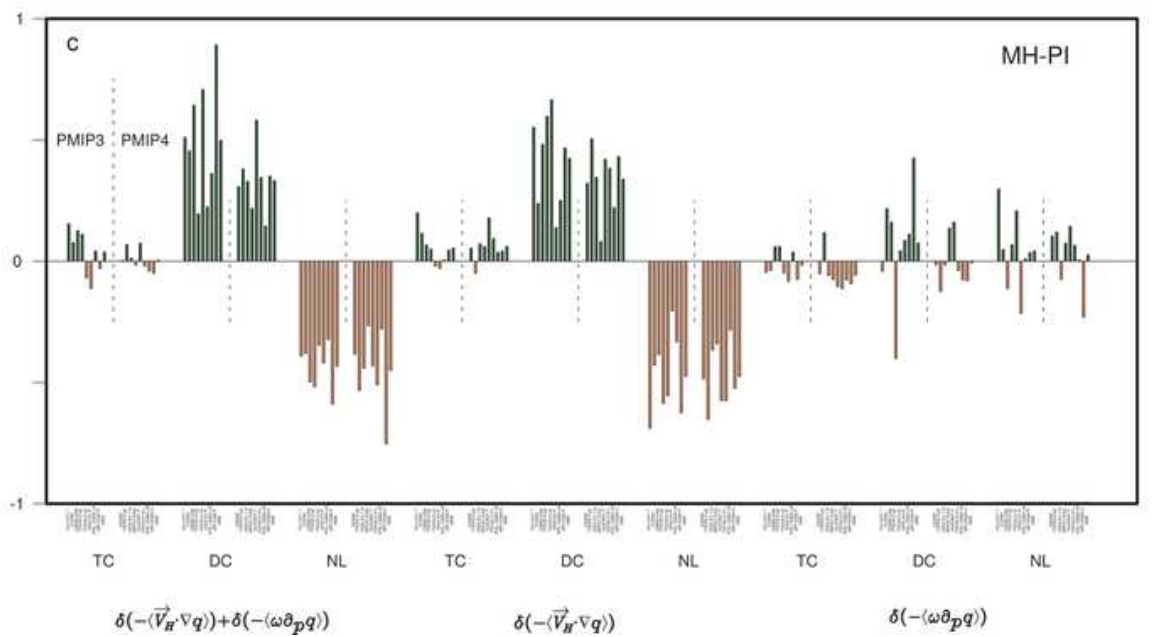

Figure 2

Results from the moisture budget equation used to resolve water vapor processes related to mean precipitation for the (a) MH and PI periods and (b) differences between the $\mathrm{MH}$ and PI periods. The two difference terms in (b) were decomposed into three processes in (c) to quantify the relative contribution from changes due to specific humidity with fixed atmospheric circulation (thermodynamic component; 
TC), atmospheric circulation with constant specific humidity (dynamic component; DC), and simultaneous changes in both specific humidity and atmospheric circulation (i.e., non-linear term; NL).
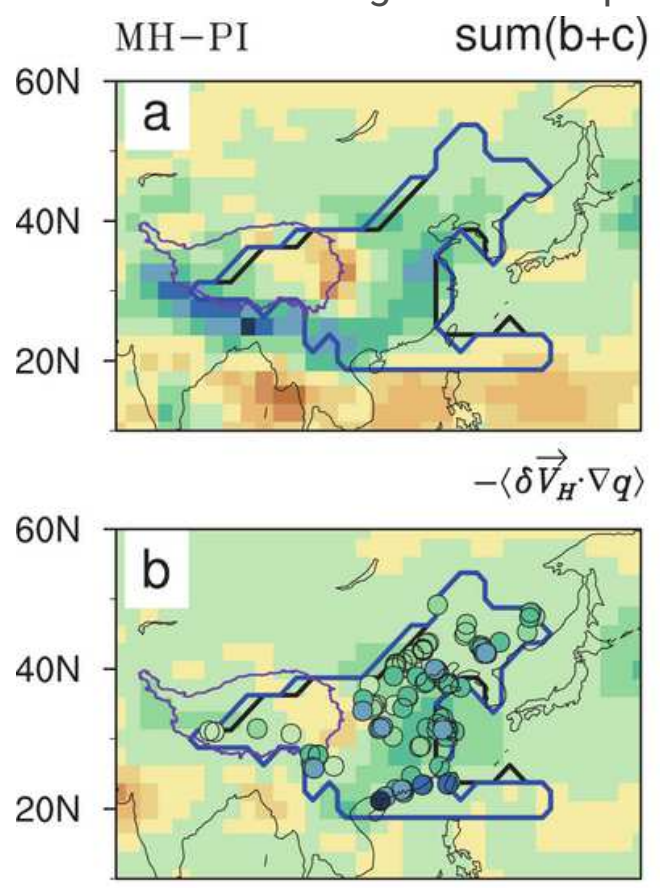

$-\left\langle\delta \omega \partial_{p} q\right\rangle$

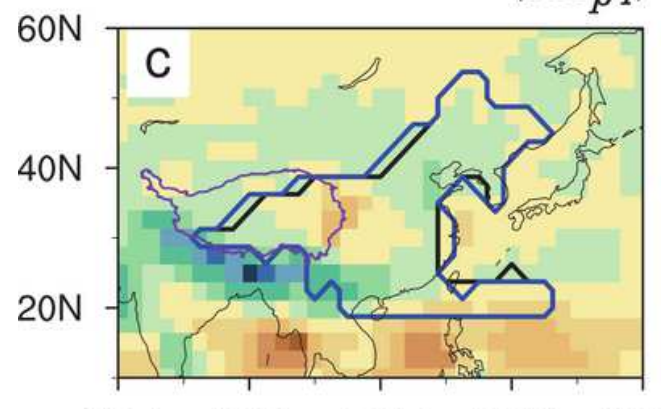

70E $\quad 90 \mathrm{E} \quad 110 \mathrm{E} \quad 130 \mathrm{E} \quad 150 \mathrm{E}$

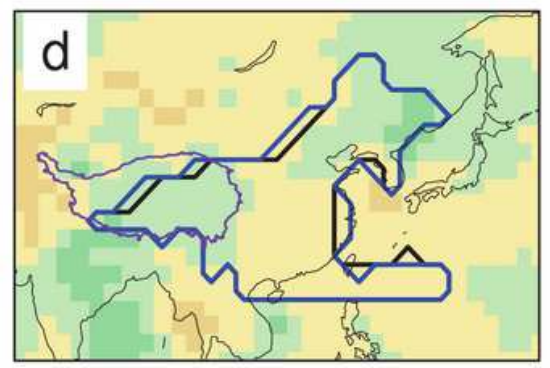

$-\left\langle\vec{V}_{H} \cdot \nabla \delta q\right\rangle$

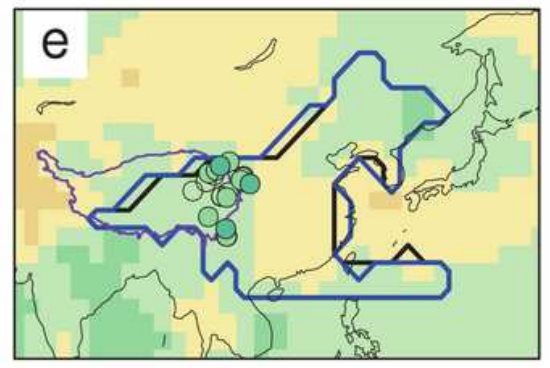

$-\langle\omega \partial p \delta q$

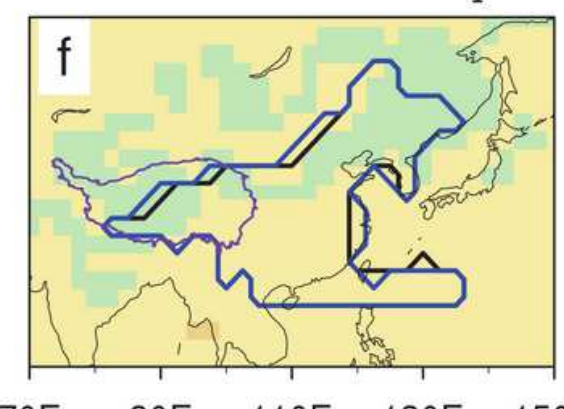

70E $\quad 90 \mathrm{E} \quad 110 \mathrm{E} \quad 130 \mathrm{E} \quad 150 \mathrm{E}$ $\operatorname{sum}(\mathrm{h}+\mathrm{i})$

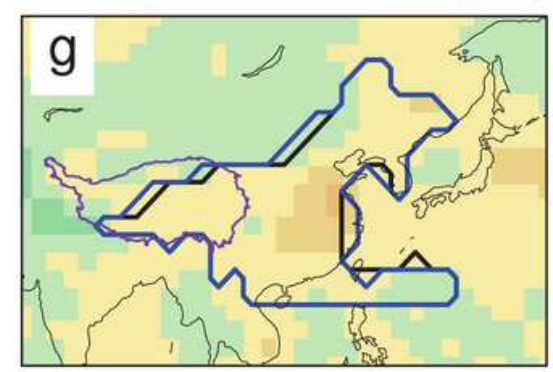

$-\left\langle\delta \vec{V}_{H} \cdot \nabla \delta q\right\rangle$

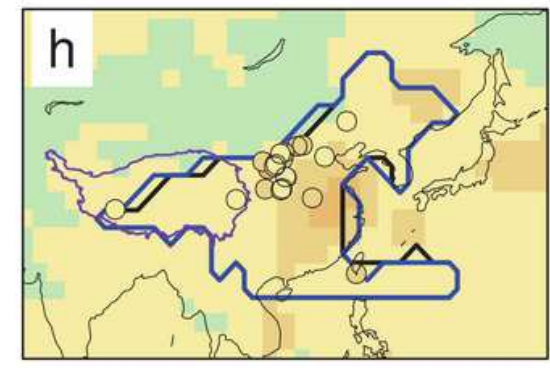

$-\left\langle\delta \omega \partial p^{\delta q}\right\rangle$

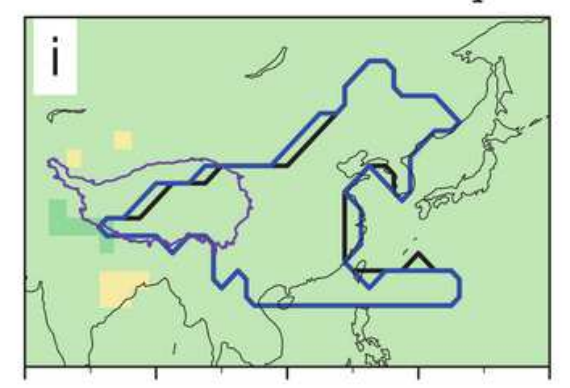

70E $\quad 90 \mathrm{E} \quad 110 \mathrm{E} \quad 130 \mathrm{E} \quad 150 \mathrm{E}$

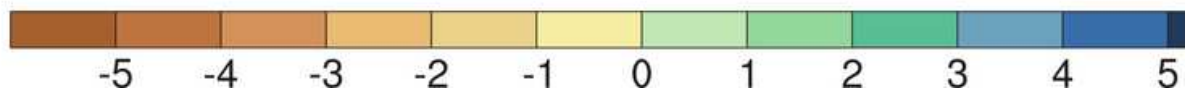

\section{Figure 3}

Pollen-based precipitation records and spatial patterns of the three decomposed processes for the two moisture advection patterns shown in Fig. 2c. The physical processes (from left to right in each subfigure) are DC, TC, and NL. (c, f, i) Vertical moisture advection. (b, e, h) Horizontal moisture advection. $(a, d, g)$ Sum of the two moisture advections. The 126 green circle symbols (106 in (b) and 20 in (e)) indicate wetter East Asia conditions, and the 21 yellow circle symbols in (h) indicate drier East Asia conditions. Note: The designations employed and the presentation of the material on this map do not imply the expression of any opinion whatsoever on the part of Research Square concerning the legal status of any country, territory, city or area or of its authorities, or concerning the delimitation of its frontiers or boundaries. This map has been provided by the authors. 

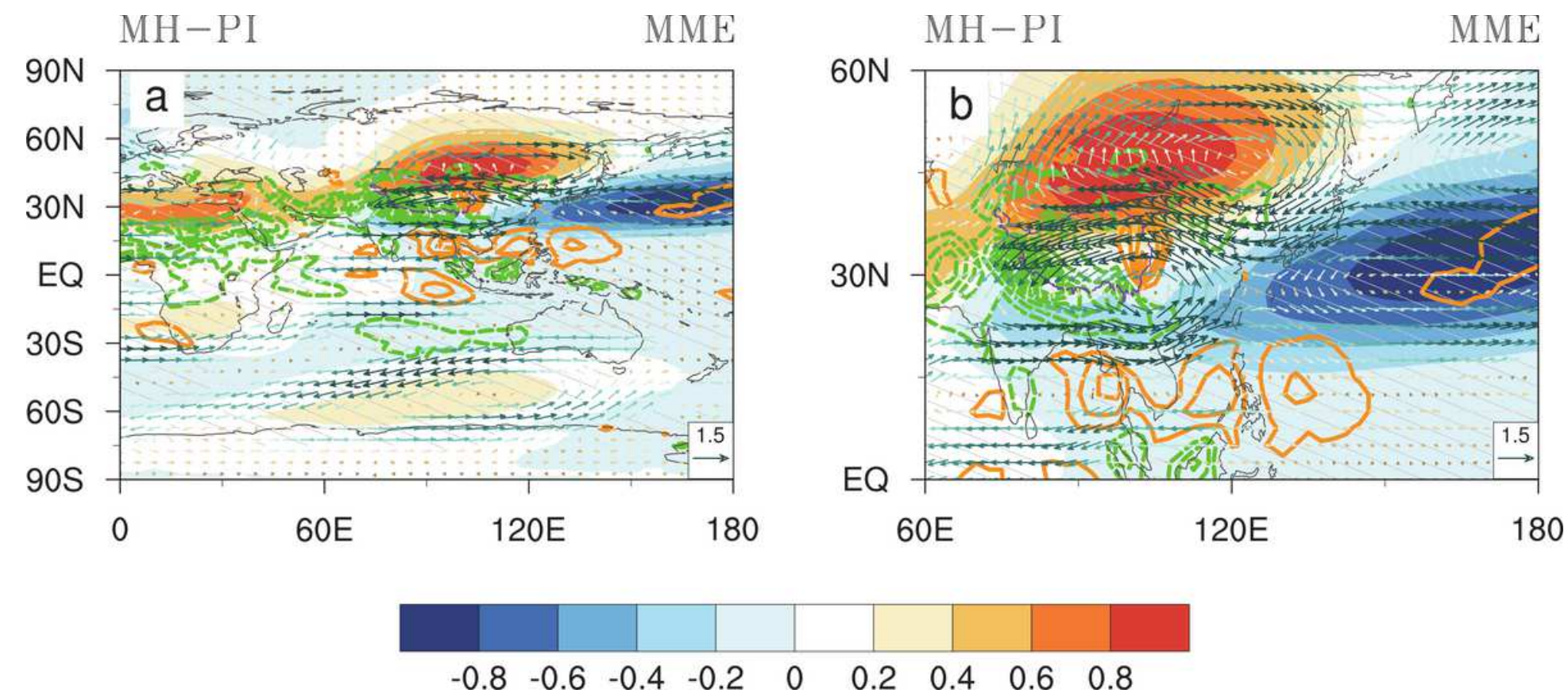

Figure 4

(a) Differences between the three vertically integrated variables throughout the troposphere between the $\mathrm{MH}$ and PI periods, which are termed the stationary eddy horizontal circulation (colored vectors; color bar not shown), stationary eddy vertical velocity (contours), and air temperature (shading with color bar). (b) Enlarged view of (a) over the EASM domain. Gray dashed lines are the stationary eddy air temperature above the $1 \%$ level. Positive vertical velocity values indicate descending motion (orange solid contours), and negative values represent ascending motion (green dashed contours). Note: The designations employed and the presentation of the material on this map do not imply the expression of any opinion whatsoever on the part of Research Square concerning the legal status of any country, territory, city or area or of its authorities, or concerning the delimitation of its frontiers or boundaries. This map has been provided by the authors. 

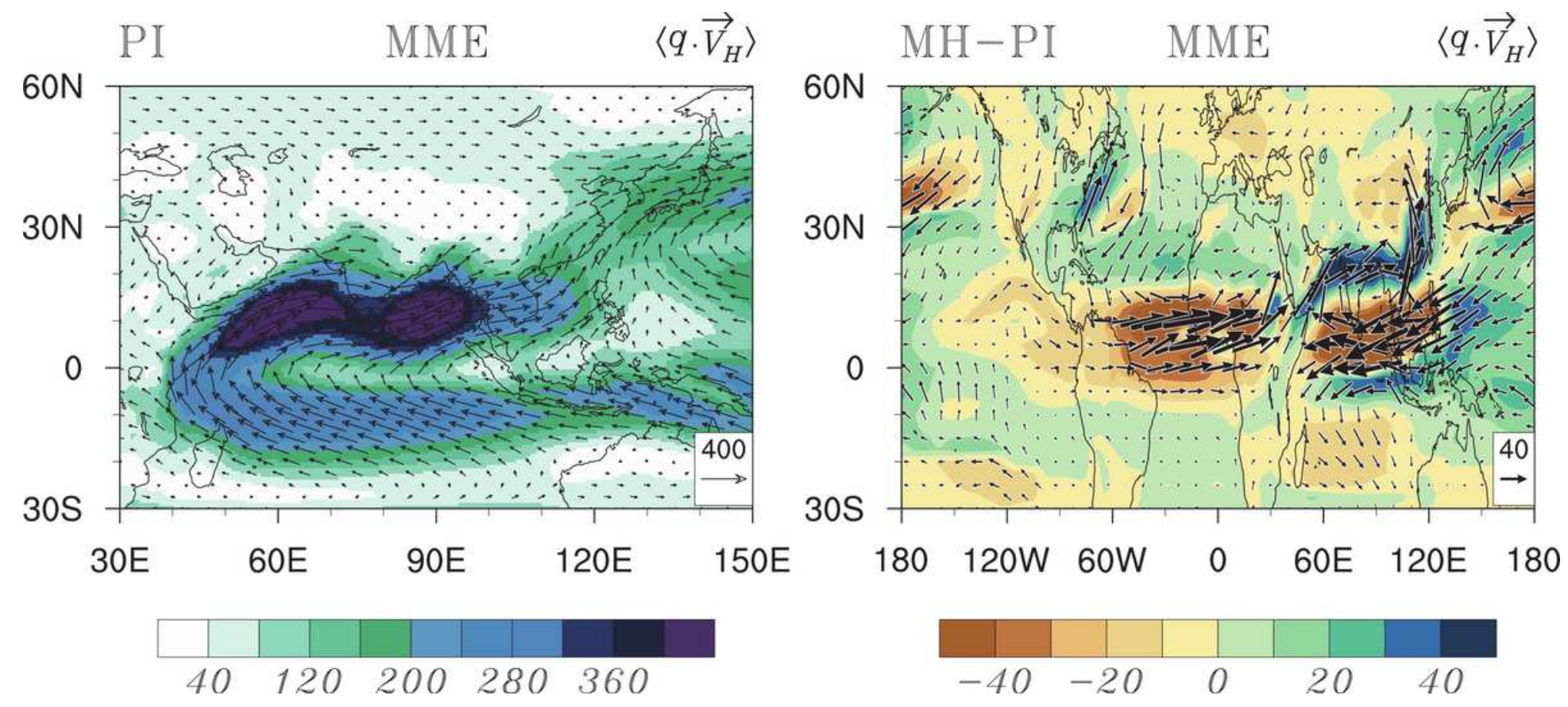

Figure 5

Please see the Manuscript PDF file for the complete figure caption. Note: The designations employed and the presentation of the material on this map do not imply the expression of any opinion whatsoever on the part of Research Square concerning the legal status of any country, territory, city or area or of its authorities, or concerning the delimitation of its frontiers or boundaries. This map has been provided by the authors. 

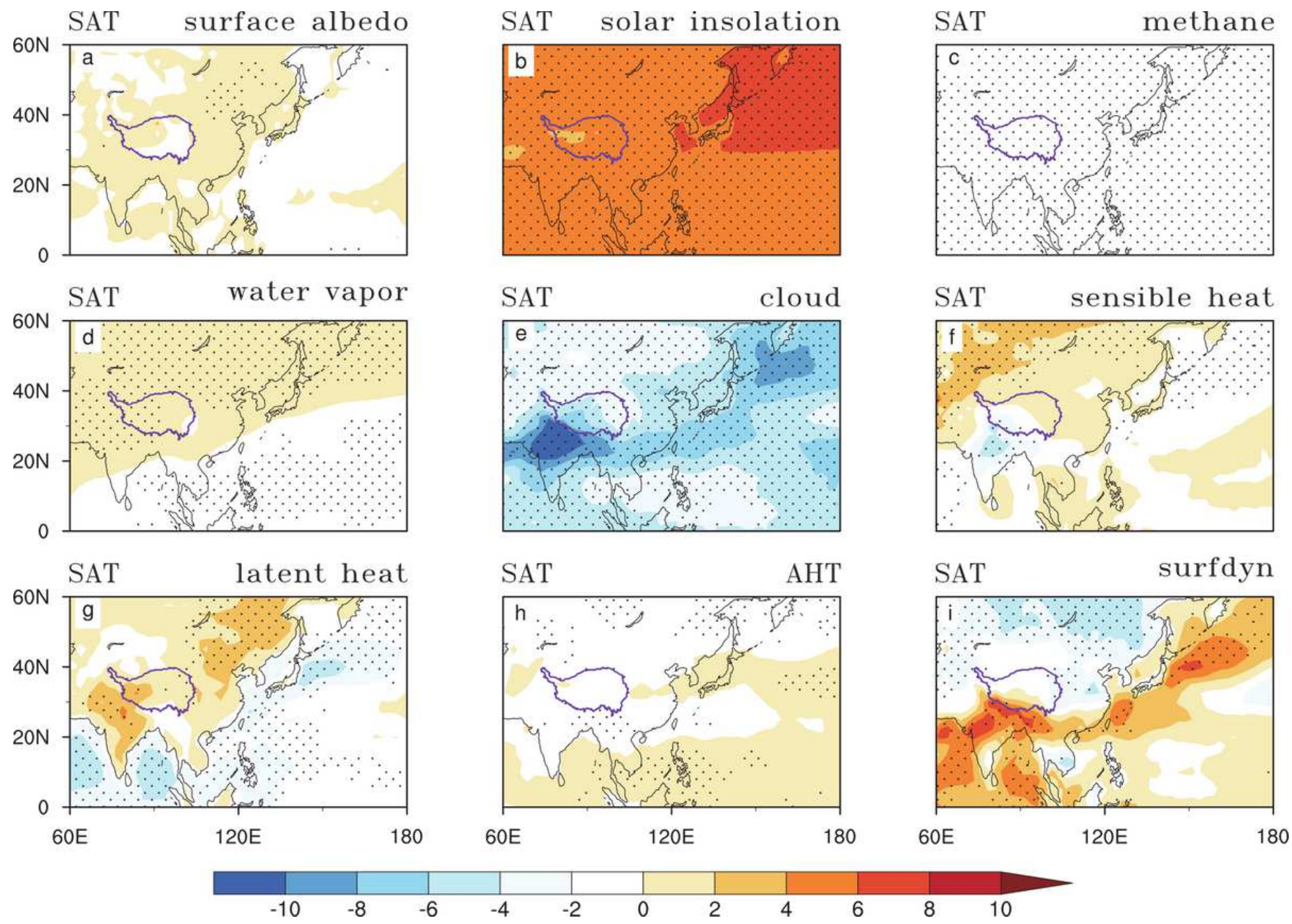

\section{Figure 6}

CFRAM-based decompositions of SAT changes $\left(\right.$ in ${ }^{\circ} \mathrm{C}$ ) in the $\mathrm{MH}$ relative to the PI period (as shown in Fig. 1a), as represented by nine processes. AHT and surfdyn in $(\mathrm{h}-\mathrm{i})$ are the atmospheric heat transport and surface dynamic processes, respectively. This decomposition was derived from an MME of PMIP3. Stippled areas show that seven of the eight models have the same sign. Note: The designations employed and the presentation of the material on this map do not imply the expression of any opinion whatsoever on the part of Research Square concerning the legal status of any country, territory, city or area or of its authorities, or concerning the delimitation of its frontiers or boundaries. This map has been provided by the authors.

\section{Supplementary Files}

This is a list of supplementary files associated with this preprint. Click to download.

- resubSupp.docx 